COMMENT

\title{
A few basic concepts in electrochemical carbon dioxide reduction
}

\author{
Karen Chan (1D) ${ }^{1 凶}$
}

In this perspective, I discuss a few basic concepts in fundamental mechanistic studies of electrochemical carbon dioxide reduction.

With the looming global environmental crisis, electrochemical $\mathrm{CO}_{2}$ reduction $\left(\mathrm{CO}_{2} \mathrm{R}\right)$ is a hot topic. Excellent perspectives on mechanistic studies ${ }^{1-3}$, practical vapor-fed devices ${ }^{4}$, and technoeconomic and system-level analyses ${ }^{5-7}$ have come out in the past few years, all with compelling visions for the future. We can also harken back to Hori's timeless review of his work over several decades ${ }^{8}$, which seeded many of the impressive advances today. But as the French maxim says: parfois, il faut reculer pour mieux sauter. Here, I showcase a few basic concepts in the fundamental mechanistic studies of $\mathrm{CO}_{2} \mathrm{R}$.

\section{What computational electrocatalysis can and cannot do}

In heterogeneous catalysis, periodic density functional theory (DFT) simulations have really enabled us to computationally explore reaction mechanisms. For electrocatalysis, the "computational hydrogen electrode" model is our standard method to determine reaction thermodynamics?. This method trivially translates simulations in vacuum to potential-dependent energetics, without requiring we simulate explicitly the ions or potential.

Our models of the electrolyte and electrochemical reaction barriers, in contrast, are far from convergent. Our field abounds with different approaches towards the electrolyte: implicit continuum models, explicit ab initio ones, or a hybrid of the two (Fig. 1a) ${ }^{10}$. We also have multiple ways to obtain the potential and the potential dependence of the reaction energetics ${ }^{11}$. While continuum approximations give us huge reductions in computational cost, we see significant deviations in solvation energies determined with implicit vs. dynamic explicit water models ${ }^{12}$. Furthermore, different ways to set up the applied potential result in differences in the computed reaction energetics ${ }^{13}$. All these challenges could contribute to the wide range in the computed energetics and mechanisms towards the various $\mathrm{C}_{2}$ products ${ }^{1}$.

Despite the difficulties in an ab initio treatment of electrochemical reaction barriers, we do need kinetics for mechanistic understanding. Case in point: our evolving understanding of $\mathrm{CO}_{(2)} \mathrm{R}$ to $\mathrm{CH}_{4}$ on $\mathrm{Cu}^{14}$. A thermodynamic analysis showed a proton-electron transfer to ${ }^{*} \mathrm{CO}$ to form ${ }^{*} \mathrm{CHO}$ to be the rate-limiting step. Considering the corresponding barriers across different materials, we suggested the transition state of this process to be the descriptor of activity. But when we simply consider the kinetics of electrochemical reactions with multiple proton-electron transfers, we see that this step cannot be rate limiting on $\mathrm{Cu}$. The corresponding Tafel plots have defining features that depend on the symmetry factor $\beta(0<\beta<1)$ for the rate-limiting step, as well as the number of proton-electron transfers preceding it, $n$. Figure $1 \mathrm{~b}$ shows the Tafel slopes and the effect of $\mathrm{pH}$ on the overpotential for alkaline solutions, where $\mathrm{H}_{2} \mathrm{O}$ as the proton donor. Experiments show

\footnotetext{
${ }^{1}$ Department of Physics, Technical University of Denmark, 2800 Kongens Lyngby, Denmark. ${ }^{凶}$ email: kchan@fysik.dtu.dk
} 
a

Approaches to the electrolyte in ab initio simulations

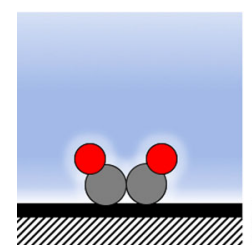

Implicit solvent

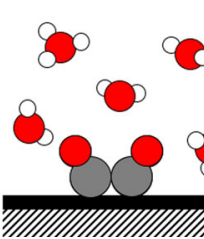

Explicit solvent (dynamic or static) b

Tafel plots of multi-step proton-electron transfer reactions (alkaline conditions)

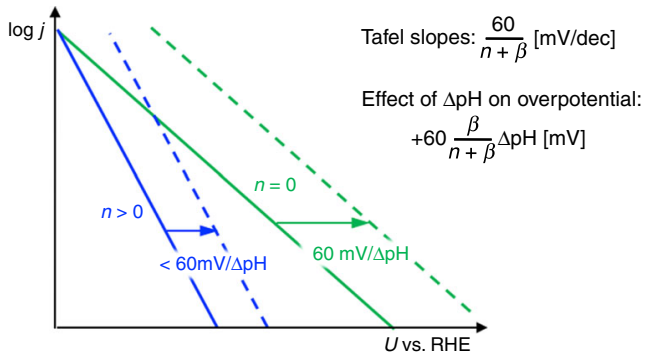

C Rate limiting steps toward $\mathrm{CO}$ and $\mathrm{C}_{2}$ products involve polar adsorbates that interact with the interfacial electric field

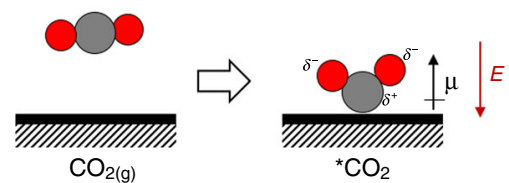

d

Origin of the $\mathrm{pH}$ effect $([\mathrm{OH}-]$ has no direct effect)

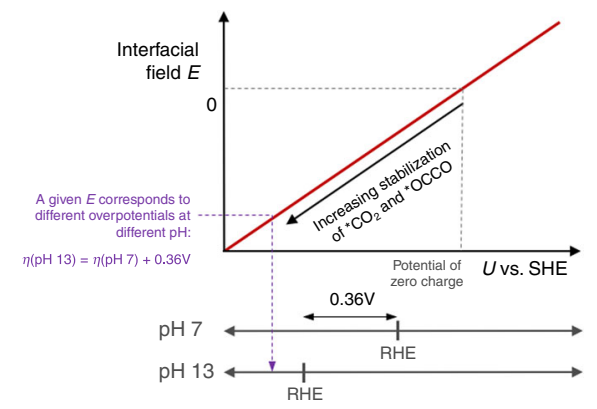

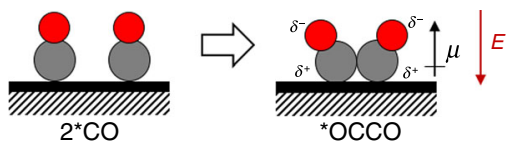

e

Effect of hydrated ion size on the interfacial field (a case of the Frumkin effect)

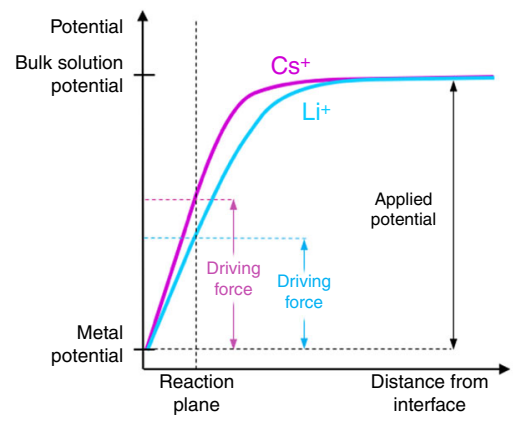

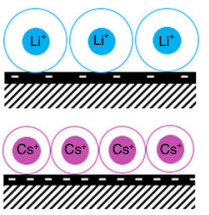

$C_{\mathrm{dll}}\left(\mathrm{Li}^{+}\right)<C_{\mathrm{dll}}\left(\mathrm{Cs}^{+}\right)$

$\left|E\left(\mathrm{Li}^{+}\right)\right|<\left|E\left(\mathrm{Cs}^{+}\right)\right|$

Fig. 1 Some basic ideas from mechanistic studies of electrochemical carbon dioxide reduction. a Implicit, explicit, and hybrid approaches to model the electrolyte in ab initio simulations. $\mathbf{b}$ In electrochemical reactions with multiple proton-electron transfers, the number of electrons $n$ transferred prior to the rate-limiting step determines both the Tafel slope and how changes in $\mathrm{pH}$ shift the activity. c Rate-limiting steps for $\mathrm{CO}_{2}$ reduction to $\mathrm{CO}$ (on weak binding catalysts) and $\mathrm{C}_{2}$ products (on $\mathrm{Cu}$ ) involve intermediates with large dipole moments $\mu$, which interact with the interfacial electric field $E$. d The absolute potential (e.g., $U$ vs. SHE) determines the electric field at an electrochemical interface and the corresponding stabilization of the polar ${ }^{*} \mathrm{CO}_{2}$ and ${ }^{\star} \mathrm{OCCO}$ intermediates. Since the dipoles point away from the interface, the field-stabilization occurs at potentials below the potential of zero charge. A given field stabilization corresponds to a more positive overpotential at higher $\mathrm{pH}$ (e.g., a $360 \mathrm{mV}$ shift between $\mathrm{pH} 7$ and 13), which leads to higher $\mathrm{CO}_{(2)} \mathrm{R}$ activity at higher $\mathrm{pH}$. e The differences in hydrated cation sizes (e.g. hydrated $\mathrm{Li}^{+}$vs. hydrated $\mathrm{Cs}^{+}$) lead to differences in the surface charge density and interfacial field at a given applied potential. This model is an example of the Frumkin effect: the interfacial field (or equivalently the local potential drop) is the driving force for electrochemical processes, and different compositions of the electric double layer give rise to different fields at a given applied potential.

$\mathrm{CH}_{4}$ activity to have a Tafel slope of $<60 \mathrm{mV} / \mathrm{dec}$, and the positive shift in overpotential with an increased $\mathrm{pH}$ is $<60 \mathrm{mV} / \mathrm{pH}$ unit, both consistent with $n>0$. Therefore, the rate-limiting step must occur after the initial proton-electron transfer to ${ }^{*} \mathrm{CO}$ to form ${ }^{*} \mathrm{CHO}$ (or $\left.{ }^{*} \mathrm{COH}^{15}\right)$. And Hori, in fact, made these observations decades ago ${ }^{8}$.

To put some numbers on what we can do today, consider the Arrhenius law,

$$
\mathrm{TOF}=A \exp \left(-\frac{E_{\mathrm{a}}}{k T}\right),
$$

where $A$ is the prefactor, TOF the turnover frequency, and $E_{\mathrm{a}}$ the activation energy. Without even considering the electrochemical environment, a typical DFT error in adsorption energy is $0.15 \mathrm{eV}^{16}$. A shift in $E_{\mathrm{a}}$ of this magnitude gives a $300 \times$ change in the TOF at room temperature! Depending on the reaction process at play, the corresponding theoretical selectivities can have uncertainties that approach $100 \%^{17}$. With electrochemical barriers, the uncertainties are compounded by the challenges mentioned above.
So DFT-based kinetic models do not presently give us predictions of activity or selectivity to the precision of experiments where mass transport and the surface structure of the catalyst are carefully controlled. With error cancellation, we have much more confidence in the relative: the relative magnitudes of barriers within a given mechanism, as well as the relative activity across catalysts $^{16}$ and across reaction conditions ${ }^{18}$. Especially with our present degree of accuracy, we should, wherever possible, couple DFT models to ample feedback from experiment. Such joint efforts have given us valuable insights into reaction mechanisms, activity descriptors, and electrolyte effects ${ }^{1}$.

\section{The activity towards $\mathrm{CO}$ and $\mathrm{C}_{2}$ products is driven by field-dipole interactions}

A special feature of $\mathrm{CO}_{(2)} \mathrm{R}$ is the importance of steps that do not involve a proton-electron transfer (Fig. 1c). On weak binding catalysts (e.g. $\mathrm{Au}^{19}$ and $\mathrm{Fe}-\mathrm{N}-\mathrm{C}^{20}$ catalysts), the rate of $\mathrm{CO}_{2} \mathrm{R}$ to $\mathrm{CO}$ is limited by $\mathrm{CO}_{2}$ adsorption. On $\mathrm{Cu}$ catalysts, $\mathrm{CO}-\mathrm{CO}$ 
coupling limits the rate of $\mathrm{CO}_{(2)}$ reduction to high-value $\mathrm{C}_{2}$ products such as ethanol and ethylene ${ }^{3}$.

Now, the dipoles of $* \mathrm{CO}_{2}$ and $*$ OCCO interact strongly with the interfacial electric field. And since the field depends on the absolute potential, e.g. on an SHE scale, so does the activity of the corresponding reactions. Figure $1 \mathrm{~d}$ shows the variation of the interfacial field $E$ and the corresponding stabilization of the polar intermediates vs. the potential $U$ vs. SHE. On the other hand, the overpotential $\eta$ depends on $U$ vs. RHE, which shifts on the SHE scale by a Nernstian factor of $60 \mathrm{mV} / \mathrm{pH}$ unit. For reduction reactions, a positive shift in $\eta$ translates to higher activity. For example, a shift in $\mathrm{pH}$ from 7 to 13 translates to a whopping shift in $\eta$ of $+0.36 \mathrm{~V}$ ! We can therefore think of the dramatic $\mathrm{pH}$ effect for these products as simply arising from a shift in the RHE reference potential.

We can use different labels for this phenomenon, such as single electron transfer ${ }^{19}$ or decoupled proton-electron transfer ${ }^{3}$, but the dipole-field vocabulary allows us to consider the reaction rate in terms of dipoles of the intermediates, $\mu$, and the interfacial capacitance, $C_{\mathrm{dl}}$. For example, the rate of $\mathrm{CO}_{2}$ adsorption and the corresponding Tafel slope are as follows ${ }^{21,22}$ :

$$
\begin{gathered}
j \propto \exp \left(-\frac{\mu\left(\mathrm{CO}_{2}\right)_{\mathrm{TS}} \cdot E}{k T}\right), \\
\text { Tafel slope }=\left|\frac{\partial U}{\partial \log j}\right| \propto \frac{1}{\mu\left(\mathrm{CO}_{2}\right)_{\mathrm{TS}} C_{\mathrm{dl}}}
\end{gathered}
$$

and we can write analogous expressions for CO dimerization.

Note that the local $\left[\mathrm{OH}^{-}\right]$, which increases with increasing $\mathrm{CO}_{(2)} \mathrm{R}$ current, plays no direct role in promoting the rate of these two steps ${ }^{23}$, since they are driven by the field alone. However, the $\left[\mathrm{OH}^{-}\right]$can alter the $\mathrm{CO}_{2}$ concentration through the bicarbonate equilibria, suppress $\mathrm{CH}_{4}$ formation ${ }^{14}$, and promote the activity towards acetate, even at a fixed $U$ vs. $\mathrm{SHE}^{24}$

These very dipole-field interactions also rationalize the sensitivity of activity to cation identity ${ }^{18}$ (Fig. 1e). In a classical picture of the interface, the ion concentration is limited by the hydrated ion size ${ }^{25}$. The smaller the size, the greater the surface charge and interfacial field for a given applied potential, which increases $C_{\mathrm{dl}}$. The slightly smaller hydrated size of $\mathrm{Cs}^{+}$vs. $\mathrm{Li}^{+}$leads to the 1-2 orders of magnitude enhancement for the $\mathrm{CO}$ activity on $\mathrm{Ag}$ and $\mathrm{C}_{2}$ activity on $\mathrm{Cu}$.

This model of the ion effects is an echo of the decades-old "Frumkin diffuse layer correction" to Butler-Volmer kinetics ${ }^{26}$. This correction accounts for the impact of the composition of the double layer on the local potential drop, which determines the corresponding reaction rate. Beyond electrostatics, specific chemical interactions between ions with the surface or adsorbate may also play a role, and both cations and anions can act as buffers $^{27,28}$.

The dependence of $\mathrm{CO}_{(2)} \mathrm{R}$ on adsorbate-field interactions shows us that, in addition to optimizing the adsorption energies of critical intermediates, we can look to tuning $C_{\mathrm{dl}}$ and $\mu$ towards higher activity (Eq. 3). Our models suggest that we can tune the former through the electrolyte, and the latter in single-atom catalysts, where the localization of charge on the active site is affected by the coordinating atoms ${ }^{22}$.

\section{We need TOF estimates to evaluate intrinsic activity, and Cu's still the best (but don't give up)}

What do we know about the activity of existing catalysts? Selectivities are often represented by Faradaic efficiencies: $\mathrm{FE}_{\mathrm{i}}=\frac{j_{i}}{j_{\mathrm{tot}}}$, where $j_{i}$ is the partial current density of product $i$ and $j_{\text {tot }}$ the total current density. While selectivities are a critical performance metric, $\mathrm{FE}_{i}$ 's can't be used to evaluate the intrinsic activity towards a given product, especially as they shift with respect to changes in the activities of all other products. The intrinsic activity, as determined by the reaction energetics, can really only be evaluated by TOFs (Eq. 1). In practice, we approximate TOFs by partial current densities normalized to the electrochemically active surface area (ECSA), $j_{\text {ECSA }} \propto \rho_{\text {site }}$ TOF, where $\rho_{\text {site }}$ is the density of the active site. Comparisons of intrinsic activity with $j_{\mathrm{ECSA}}$ are therefore accurate within the variations of $\rho_{\text {site }}$ among samples, the uncertainty in the ECSA, and the degree of mass transport limitations.

Surface reaction energetics on different facets typically differ by $0.1-1 \mathrm{eV}^{29}$, which translates to variations in the corresponding TOFs by orders of magnitude (Eq. 1). Shifts in $j_{\mathrm{ECSA}}$ of around an order of magnitude (or less) between catalysts with different surface structures are more likely to arise from a change in $\rho_{\text {site }}$ than a change in the predominant active site or facet. Recent reviews have shown that nano-structured $\mathrm{Cu}$ and $\mathrm{Cu}$-based bimetallics show similar $j_{\mathrm{ECSA}}$ to those on $\mathrm{Cu}$ foils ${ }^{1,2}$. To date, I am not aware of a new catalyst with intrinsic activity towards $C_{2}$ products that unequivocally exceeds that of $\mathrm{Cu}$ foil. Ongoing efforts to obtain single crystal measurements with product quantification can rigorously evaluate theoretical predictions of the most active $\mathrm{Cu}$ facet(s).

The increased $\mathrm{C}_{2}$ selectivities on various high surface area $\mathrm{Cu}$ catalysts actually arise from the suppression of other products, such as $\mathrm{CH}_{4}$ and $\mathrm{H}_{2}{ }^{1,2}$. Under alkaline conditions, $\mathrm{H}_{2}$ suppression cannot arise from local changes in $\mathrm{pH}$, since $\mathrm{H}_{2} \mathrm{O}$ is the proton donor. Perhaps nanostructuring shifts the structure and activity of water, such that products that are limited by proton-electron transfer steps are suppressed.

And why haven't we found alternatives to $\mathrm{Cu}$ that either match or exceed its intrinsic activity towards $\mathrm{C}_{2}$ products? Stability is a possible culprit: leaching or surface restructuring, which can be driven by the presence of elements that strongly bind *CO. But I know no fundamental limitation on the existence of stable and active alternatives, especially if we expand our search to emergent classes of materials beyond binary combinations of transition metals ${ }^{30,31}$. Furthermore, improvements in catalytic efficiency are still needed ${ }^{5,6}$. With a rigorous consideration of surface stability, the discovery of new catalysts beyond $\mathrm{Cu}$ remains a worthwhile and important pursuit.

\section{Outlook}

Even as we develop practical devices and systems for $\mathrm{CO}_{2} \mathrm{R}$, we still face fundamental challenges at the level of reaction mechanisms and intrinsic activity. These challenges range from simulating electrochemical kinetics to the discovery of new catalysts beyond $\mathrm{Cu}$. Tremendous opportunity lies in overcoming them. With the increasing dialogue among us and the diversity of expertise we are bringing together-I envision that our collective efforts will ultimately contribute to establishing a sustainable carbon cycle.

Received: 4 September 2020; Accepted: 8 October 2020; Published online: 23 November 2020

\section{References}

1. Nitopi, S. et al. Progress and perspectives of electrochemical $\mathrm{CO} 2$ reduction on copper in aqueous electrolyte. Chem. Rev. 119, 7610-7672 (2019).

2. Resasco, J. \& Bell, A. T. Electrocatalytic $\mathrm{CO} 2$ reduction to fuels: progress and opportunities.Trends Chem. 2(1), 12 (2020).

3. Kortlever, R., Shen, J., Schouten, K. J. P., Calle-Vallejo, F. \& Koper, M. T. M. M. Catalysts and reaction pathways for the electrochemical reduction of carbon dioxide. J. Phys. Chem. Lett. 6, 4073-4082 (2015).

4. Higgins, D., Hahn, C., Xiang, C., Jaramillo, T. F. \& Weber, A. Z. Gas-diffusion electrodes for carbon dioxide reduction: a new paradigm. ACS Energy Lett. 4, 317-324 (2019). 
5. Jouny, M., Luc, W. \& Jiao, F. General techno-economic analysis of $\mathrm{CO}_{2}$ electrolysis systems. Ind. Eng. Chem. Res. 57, 2165-2177 (2018).

6. Verma, S. et al. A gross-margin model for defining technoeconomic benchmarks in the electroreduction of $\mathrm{CO}_{2}$. ChemSusChem 9, 1-9 (2016).

7. Smith, W. A., Burdyny, T., Vermaas, D. A. \& Geerlings, H. Pathways to industrial-scale fuel out of thin air from $\mathrm{CO}_{2}$ electrolysis. Joule 3, 1822-1834 (2019).

8. Hori, Y. In Modern Aspects of Electrochemistry (eds Vayenas, C. G. et al.) 89-189 (Springer, New York, 2008).

9. Nørskov, J. K. et al. Origin of the overpotential for oxygen reduction at a fuelcell cathode. J. Phys. Chem. B 108, 17886-17892 (2004).

10. Schwarz, K. \& Sundararaman, R. The electrochemical interface in firstprinciples calculations. Surf. Sci. Rep. 75, 100492 (2020).

11. Groß, A. Theory of solid/electrolyte interfaces. Surf. Interface Sci. 8, 471-515 (2020).

12. Heenen, H. H., Gauthier, J. A., Kristoffersen, H. H., Ludwig, T. \& Chan, K. Solvation at metal/water interfaces: an ab initio molecular dynamics benchmark of common computational approaches. J. Chem. Phys. 152, 144703 (2020)

13. Gauthier, J. A. et al. Unified approach to implicit and explicit solvent simulations of electrochemical reaction energetics. J. Chem. Theory Comput. 15, 6895-6906 (2019).

14. Liu, $\mathrm{X}$. et al. pH effects on the electrochemical reduction of $\mathrm{CO} 2$ towards $\mathrm{C} 2+$ products on stepped copper. Nat. Commun. 10, 32 (2019).

15. Nie, X., Esopi, M. R., Janik, M. J. \& Asthagiri, A. Selectivity of $\mathrm{CO}_{2}$ reduction on copper electrodes: the role of the kinetics of elementary steps. Angew. Chem. Int. Ed. 52, 2459-2462 (2013).

16. Medford, A. J. et al. Assessing the reliability of calculated catalytic ammonia synthesis rates. Science 345, 197-200 (2014).

17. Yang, N. et al. Intrinsic selectivity and structure sensitivity of rhodium catalysts for $\mathrm{C}_{2+}$ oxygenate production. J. Am. Chem. Soc. 138, 3705-3714 (2016).

18. Ringe, $\mathrm{S}$. et al. Understanding cation effects in electrochemical $\mathrm{CO} 2$ reduction. Energy Environ. Sci. 12, 3001-3014 (2019).

19. Wuttig, A., Yaguchi, M., Motobayashi, K., Osawa, M. \& Surendranath, Y. Inhibited proton transfer enhances Au-catalyzed $\mathrm{CO}_{2}$-to-fuels selectivity. Proc. Natl Acad. Sci. USA 113, E4585-E4593 (2016).

20. Varela, A. S. et al. pH Effects on the selectivity of the electrocatalytic $\mathrm{CO}_{2}$ reduction on graphene-embedded $\mathrm{Fe}-\mathrm{N}-\mathrm{C}$ motifs: bridging concepts between molecular homogeneous and solid-state heterogeneous catalysts. ACS Energy Lett. 3, 812-817 (2018).

21. Ringe, $\mathrm{S}$. et al. Double layer charging driven carbon dioxide adsorption limits the rate of electrochemical carbon dioxide reduction on gold. Nat. Commun. 11, 33 (2020).

22. Vijay, S. et al. Dipole-field interactions determine the $\mathrm{CO}_{2}$ reduction activity of 2D Fe-N-C single atom catalysts. ACS Catal. 10, 7826-7835 (2020).

23. $\mathrm{Li}$, J. et al. Hydroxide is not a promoter of $\mathrm{C}_{2+}$ product formation in the electrochemical reduction of CO on copper. Angew. Chem. Int. Ed. 59, 4464-4469 (2020).

24. Luc, W. et al. Two-dimensional copper nanosheets for electrochemical reduction of carbon monoxide to acetate. Nat. Catal. 2, 423-430 (2019).

25. Borukhov, I., Andelman, D. \& Orland, H. Adsorption of large ions from an electrolyte solution: a modified Poisson-Boltzmann equation. Electrochim. Acta 46, 221-229 (2000)
26. Bard, A. J. \& Faulkner, L. R. Electrochemical Methods: Fundamentals and Applications, 2nd edn (John Wiley \& Sons, 2000).

27. Singh, M. R., Kwon, Y., Lum, Y., Ager, J. W. \& Bell, A. T. Hydrolysis of electrolyte cations enhances the electrochemical reduction of $\mathrm{CO}_{2}$ over $\mathrm{Ag}$ and Cu. J. Am. Chem. Soc. 138, 13006-13012 (2016).

28. Zhang, F. \& Co, A. C. Direct evidence of local pH change and the role of alkali cation during $\mathrm{CO} 2$ electroreduction in aqueous media. Angew. Chemie Int. Ed. 59, 1674-1681 (2020).

29. Nørskov, J. K., Studt, F., Abild-Pedersen, F. \& Bligaard, T. Fundamental Concepts in Heterogeneous Catalysis (John Wiley and Sons, 2014).

30. Piontek, S. et al. Bio-inspired design: bulk iron-nickel sulfide allows for efficient solvent-dependent $\mathrm{CO}_{2}$ reduction. Chem. Sci. 10, 1075-1081 (2019).

31. Pedersen, J. K., Batchelor, T. A. A., Bagger, A. \& Rossmeisl, J. High-entropy alloys as catalysts for the $\mathrm{CO}_{2}$ and $\mathrm{CO}$ reduction reactions. ACS Catal. 10 2169-2176 (2020)

\section{Acknowledgements}

This work was supported by a research grant (9455) from VILLUM FONDEN. I thank Hugh Simons, Nitish Govindarajan, Sudarshan Vijay, and Brian Seger for their writing feedback.

\section{Author contributions}

K.C. conceived and wrote the piece.

\section{Competing interests}

The author declares no competing interests.

\section{Additional information}

Correspondence and requests for materials should be addressed to K.C.

Reprints and permission information is available at http://www.nature.com/reprints

Publisher's note Springer Nature remains neutral with regard to jurisdictional claims in published maps and institutional affiliations.

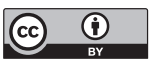

Open Access This article is licensed under a Creative Commons Attribution 4.0 International License, which permits use, sharing, adaptation, distribution and reproduction in any medium or format, as long as you give appropriate credit to the original author(s) and the source, provide a link to the Creative Commons license, and indicate if changes were made. The images or other third party material in this article are included in the article's Creative Commons license, unless indicated otherwise in a credit line to the material. If material is not included in the article's Creative Commons license and your intended use is not permitted by statutory regulation or exceeds the permitted use, you will need to obtain permission directly from the copyright holder. To view a copy of this license, visit http://creativecommons.org/ licenses/by/4.0/.

(c) The Author(s) 2020 